\title{
Synthesis, Crystal Structure and Magnetic Properties of Bixbyite-type Vanadium Oxide Nitrides
}

\author{
Suliman Nakhal ${ }^{\mathrm{a}}$, Wilfried Hermes ${ }^{\mathrm{b}}$, Thorsten Ressler ${ }^{\mathrm{a}}$, Rainer Pöttgen ${ }^{\mathrm{b}}$, and Martin Lerch $^{\mathrm{a}}$ \\ ${ }^{a}$ Institut für Chemie, TU Berlin, Straße des 17. Juni 135, 10623 Berlin, Germany \\ b Institut für Anorganische und Analytische Chemie and NRW Graduate School of Chemistry, \\ Westfälische Wilhelms-Universität Münster, Corrensstraße 30, 48149 Münster, Germany \\ Reprint requests to M. Lerch. E-mail: lerch@ chem.tu-berlin.de
}

Z. Naturforsch. 2009, 64b, 281 -286; received December 12, 2008

Ammonolysis of vanadium sulfide leads to the formation of bixbyite-type vanadium oxide nitrides.
Small amounts of nitrogen incorporated in the structure result in the stabilization of the bixbyite type
not known for vanadium oxides. The crystal structure was investigated using X-ray diffraction and
X-ray absorption spectroscopy. At temperatures above $550{ }^{\circ} \mathrm{C}$ the powders decompose to corundum-
type $\mathrm{V}_{2} \mathrm{O}_{3}$ containing no detectable amount of nitrogen. Below $39 \mathrm{~K}$ magnetic ordering is observed.

Key words: Oxide Nitrides, Crystal Chemistry, Bixbyite

\section{Introduction}

In the last years nitrides and oxide nitrides have become shifted more and more in the focus of interest. In particular transition metal oxide nitrides are an interesting group of materials with physical properties making them candidates for technical applications. For example, they are candidates as photocatalysts for water splitting under sunlight [1-3]. Ionic conductivity studies focusing on the behavior of $\mathrm{N}^{3-}$ anions have yielded promising results indicating the possibility of $\mathrm{N}^{3-}$ ion conducting materials [4-6]. Transition metal oxide nitrides are also compounds possibly suitable as dielectrics $[7,8]$ in microelectronic devices, or as chemical gas sensors [9].

In contrast to the chemistry of oxide nitrides of transition metals such as tantalum or zirconium, where a lot of work was done in the last years, the knowledge of the related type of compounds of vanadium is not so extensive. More than thirty years ago Brauer and Reuther reported the first vanadium oxide nitrides [10], all structurally derived from the rock salt type. These non-stoichiometric compounds are metallic, and there is no evidence for magnetic ordering [11]. The possibility of a high-pressure synthesis of stoichiometric VON (a semiconductor) has been predicted by Lumey and Dronskowski [12].

In this contribution we report on the synthesis, crystal structure, and magnetic properties of vanadium oxide nitrides which can be formally described by partial substitution of oxygen by nitrogen in well-known vanadium sesquioxide. $\mathrm{V}_{2} \mathrm{O}_{3}$ displays a number of electronic, magnetic and structural properties that are challenging to interpret and explain [13-18]. At r.t. $\mathrm{V}_{2} \mathrm{O}_{3}$ exhibits the corundum structure, it is metallic and paramagnetic. It is unique among other isostructural sesquioxides with respect to its small $a / c$ ratio and metallic conductivity. On reducing the temperature, corundum-type $\mathrm{V}_{2} \mathrm{O}_{3}$ shows a structural phase transition to a monoclinic structure at around $150 \mathrm{~K}$. Accompanying the transition, a change from metallic to insulating behavior and the onset of antiferromagnetic ordering are observed. The metal-insulator transition is viewed as a Mott transition.

\section{Experimental Section}

Synthesis and chemical analysis

$\mathrm{V}_{5.45} \mathrm{~S}_{8}$ is the basis compound the materials described in this study are derived from. It can be prepared by reacting $\mathrm{V}_{2} \mathrm{O}_{5}$ or $\mathrm{NH}_{4} \mathrm{VO}_{3}$ with flowing $\mathrm{H}_{2} \mathrm{~S}$ gas at $800-$ $950{ }^{\circ} \mathrm{C}$ for $2 \mathrm{~h}$. The vanadium sulfide obtained was converted into oxide nitrides by reaction with wet ammonia gas (3.8, Messer-Griesheim) at a constant flow rate of $15-20 \mathrm{~L} \mathrm{~h}^{-1}$ at temperatures of $325-500{ }^{\circ} \mathrm{C}$ for $20 \mathrm{~h}$. EDX-analyses of the oxide nitrides obtained gave no indications for residual sulfur. Nitrogen and oxygen contents were determined using a LECO TC-300 / EF-300 N/O analyzer (hot gas extraction). The accuracy is $\sim 2 \%$ of the N/O contents present.

\section{Structure determination}

A Siemens D5000 powder diffractometer $\left(\mathrm{Cu} K_{\alpha 1}\right.$ radiation, $\lambda=154.06 \mathrm{pm}$, position-sensitive detector) was used for 


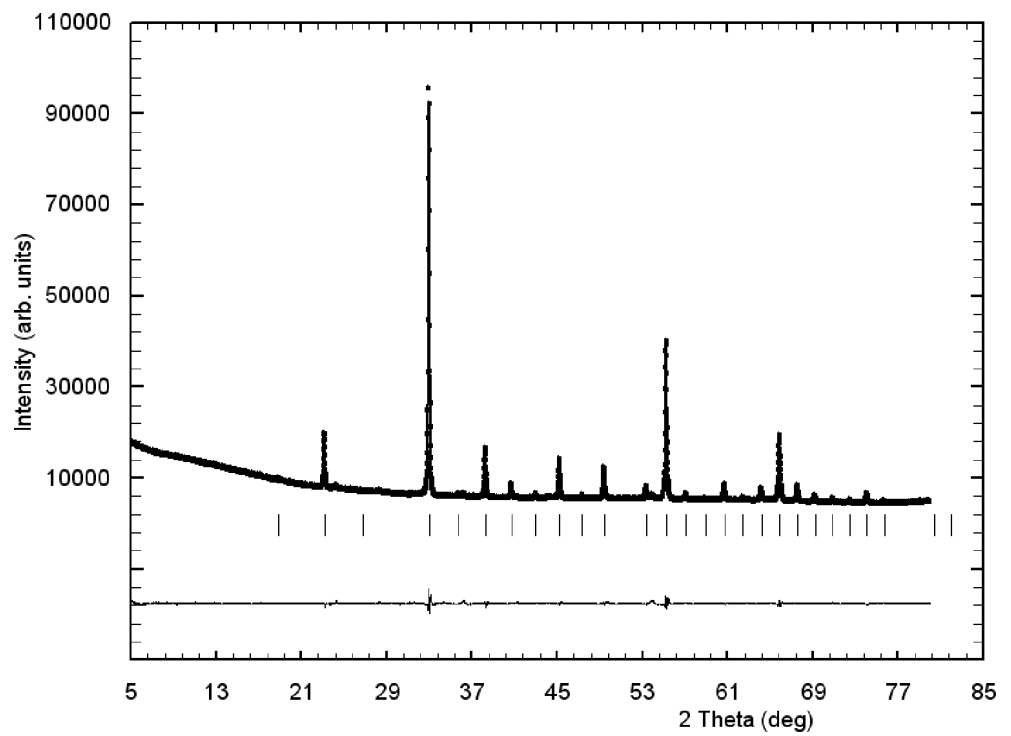

Fig. 1. X-Ray powder diffraction diagram of $\mathrm{V}_{2} \mathrm{O}_{3.07} \mathrm{~N}_{0.13}$ with the results of the Rietveld refinement. the XRD measurements at r.t. Temperature dependent measurements (samples in $\mathrm{SiO}_{2}$-glass capillaries under argon) were carried out using a Stoe STADI-P powder diffractometer $\left(\mathrm{Mo} K_{\alpha 1}\right.$ radiation, $\lambda=70.93 \mathrm{pm}$, imaging plate detector) with a graphite-heated resistance furnace. The program packages POWDER CELL 2.4 [19] and FULLPROF 2006 [20] were used for structural refinements. The peak profiles were fitted with a pseudo-Voigt function.

\section{X-Ray absorption spectroscopy}

In situ transmission XAS experiments were performed at the V K edge (5.465 keV, Si 111) at beamline E4 at the Hamburg Synchrotron Radiation Laboratory, HASYLAB. The storage ring operated at $4.4 \mathrm{GeV}$ with injection currents of $150 \mathrm{~mA}$. The materials were mixed with polyethylene ( $\sim 5 \mathrm{mg}$ oxide nitride (or oxide) and $\sim 30 \mathrm{mg} \mathrm{PE}$ ) and pressed with a force of $2 \mathrm{t}$ into a pellet (13 $\mathrm{mm}$ diameter). $\mathrm{X}$-Ray absorption fine structure (XAFS) analysis was performed using the software WINXAS v3.1 [21]. Background subtraction and normalization were carried out by fitting linear polynomials to the pre-edge and the post-edge region of the absorption spectra, respectively. The extended X-ray absorption fine structure (EXAFS) data $\chi(k)$ was extracted by using cubic splines to obtain a smooth atomic background, $\mu_{0}(k)$. The pseudo radial distribution function $\mathrm{FT}\left(\chi(k) \times k^{3}\right)$ was calculated by Fourier transforming the $k^{3}$-weighted experimental $\chi(k)$ function, multiplied by a Bessel window, into the $R$ space. EXAFS data analysis was performed using theoretical backscattering phases and amplitudes calculated with the $a b$ initio multiple-scattering code FEFF7 [22]. Single-scattering and multiple-scattering paths in the $\mathrm{V}_{2} \mathrm{O}_{3}$ model structure were calculated up to $6.0 \AA$ with a lower limit of $2.0 \%$ in amplitude with respect to the strongest backscattering path. EXAFS refinements were performed in $\mathrm{R}$ space simultaneously to the magnitude and the imaginary part of a Fourier transformed $k^{3}$-weighted and $k^{1}$-weighted experimental $\chi(k)$ data set using the standard EXAFS formula [23]. Structural parameters that have been determined by a least-squares refinement of a theoretical XAFS spectrum calculated for a $\mathrm{V}_{2} \mathrm{O}_{3}$ model structure to the experimental XAFS spectrum are (i) one overall $E_{0}$ shift, (ii) DebyeWaller factors for single-scattering paths, and (iii) distances of single-scattering paths. Coordination numbers $(\mathrm{CN})$ and $S_{0}^{2}$ were kept invariant in the refinement.

\section{Magnetic susceptibility measurements}

The $\mathrm{V}_{2} \mathrm{O}_{3.07} \mathrm{~N}_{0.13}$ sample was packed in kapton foil and attached to the sample holder rod of a VSM for measuring the magnetic properties in a Quantum Design PhysicalProperty-Measurement-System in the temperature range 3 $300 \mathrm{~K}$ with magnetic flux densities up to $80 \mathrm{kOe}$.

\section{Results and Discussion}

Bixbyite-type vanadium oxide nitrides in the composition range between $\mathrm{V}_{2} \mathrm{O}_{3.08} \mathrm{~N}_{0.02}$ and $\mathrm{V}_{2} \mathrm{O}_{3.07}$ $\mathrm{N}_{0.13}$ have been prepared. As an example, an X-ray powder diffraction diagram of $\mathrm{V}_{2} \mathrm{O}_{3.07} \mathrm{~N}_{0.13}$ with the results of the Rietveld refinement is depicted in Fig. 1. Tables 1 and 2 present the refined structural data. In the well-known bixbyite-type structure, which can be considered a superstructure of the fluorite type, vanadium cations occupy the $8 a(0,0,0)$ and $24 d$ 
Table 1. Refined structural data for $\mathrm{V}_{2} \mathrm{O}_{3.07} \mathrm{~N}_{0.13}$.

\begin{tabular}{ll}
\hline Structure type & bixbyite \\
Space group & $I a \overline{3}$ \\
Crystal system & cubic \\
Lattice parameter $a, \mathrm{pm}$ & $939.66(1)$ \\
Unit cell volume $V, \mathrm{pm}^{3}$ & $829.69(2) \times 10^{6}$ \\
Formula units $Z$ & 16 \\
Calculated density $\rho, \mathrm{g} \mathrm{cm}^{-3}$ & 4.89 \\
Diffractometer & Siemens D5000 \\
Wavelength, pm & 154.06 \\
$2 \theta$ range, deg & $5-80$ \\
$R_{\mathrm{wp}}$ & 0.022 \\
$R_{\mathrm{Bragg}}$ & 0.009 \\
$R_{\exp }$ & 0.012 \\
$S$ & 1.67 \\
\hline
\end{tabular}

Table 2. Refined atomic parameters for $\mathrm{V}_{2} \mathrm{O}_{3.07} \mathrm{~N}_{0.13}$.

\begin{tabular}{llllll}
\hline Atom & W. site & $x$ & $y$ & $z$ & $B_{\text {iso }}\left(\AA^{2}\right)$ \\
\hline V1 & $8 a$ & 0 & 0 & 0 & $1.5(1)$ \\
V2 & $24 d$ & $0.2823(1)$ & 0 & $1 / 4$ & $1.42(7)$ \\
$\mathrm{O} / \mathrm{N}$ & $48 e$ & $0.1422(4)$ & $0.1290(5)$ & $-0.0944(3)$ & $0.86(7)$ \\
\hline
\end{tabular}

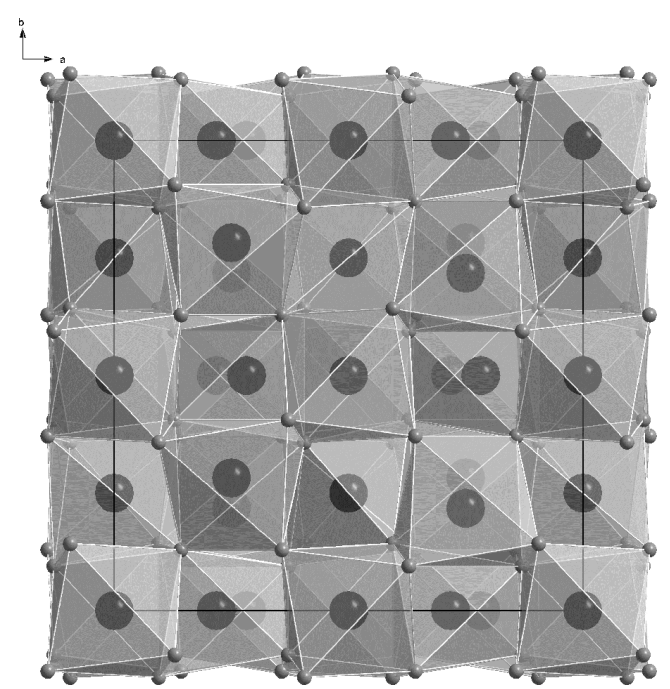

Fig. 2. Unit cell of bixbyite-type $\mathrm{V}_{2} \mathrm{O}_{3.07} \mathrm{~N}_{0.13}$ with the connectivity of the $\mathrm{V}(\mathrm{O} / \mathrm{N})_{6}$ octahedra.

$(x, 0,1 / 4)$ Wyckoff positions, and the oxide/nitride anions the general position 48e. Fig. 2 shows the unit cell. All cations are octahedrally coordinated by six anions, which are surrounded tetrahedrally by four vanadium ions. Details are given in Fig. 3 and Table 3. The bixbyite type is also known from other transition metal oxide nitrides, for example $\mathrm{Zr}_{2} \mathrm{ON}_{2}$ and $\mathrm{Hf}_{2} \mathrm{ON}_{2}$ [24-27], and from $\mathrm{V}_{2} \mathrm{O}_{2.70} \mathrm{~N}_{0.15} \mathrm{~F}_{0.15}$ [28]. From the oxide nitride compounds it is also known that the bixbyite structure tolerates a partial occupation of the anion vacancies, which are fully occupied
Table 3. Type and number $(N)$ of atoms at distance $R$ from the $\mathrm{V}$ center in $\mathrm{V}_{2} \mathrm{O}_{3.07} \mathrm{~N}_{0.13}$ obtained from a refinement of a bixbyite model structure (Tables 1 and 2) to the experimental $\mathrm{V} K$ edge XAFS functions $\chi(k)$ ( $k$ ranges from 2.0 to $11.1 \AA^{-1}, R$ ranges from 1.1 to $5.1 \AA, S_{\mathrm{o}}{ }^{2}=0.9$ (fix), $E_{0}=$ $-6.0 \mathrm{eV}$, residual $=4.9, N_{\text {ind }}=25, N_{\text {free }}=20$ ). The uncertainty in the distances amounts to about $0.03 \AA$.

\begin{tabular}{lllll}
\hline Type & $N$ & $\begin{array}{l}R(\AA) \\
\text { model } \mathrm{V}_{2} \mathrm{O}_{3}\end{array}$ & $\begin{array}{l}R(\AA) \\
\mathrm{V}_{2} \mathrm{O}_{3.07} \mathrm{~N}_{0.13}\end{array}$ & $\begin{array}{l}\sigma^{2}\left(\AA^{2}\right) \\
\mathrm{V}_{2} \mathrm{O}_{3.07} \mathrm{~N}_{0.13}\end{array}$ \\
\hline $\mathrm{V}-\mathrm{O}$ & 2 & 1.97 & 1.902 & 0.0254 \\
$\mathrm{~V}-\mathrm{O}$ & 2 & 2.01 & 1.998 & 0.00318 \\
$\mathrm{~V}-\mathrm{O}$ & 2 & 2.06 & 2.026 & 0.00127 \\
$\mathrm{~V}-\mathrm{V}$ & 2 & 3.12 & 3.116 & 0.00392 \\
$\mathrm{~V}-\mathrm{V}$ & 4 & 3.13 & 3.123 & 0.00734 \\
$\mathrm{~V}-\mathrm{V}$ & 4 & 3.54 & 3.55 & 0.00692 \\
$\mathrm{~V}-\mathrm{V}$ & 2 & 4.70 & 4.698 & 0.00271 \\
\hline
\end{tabular}

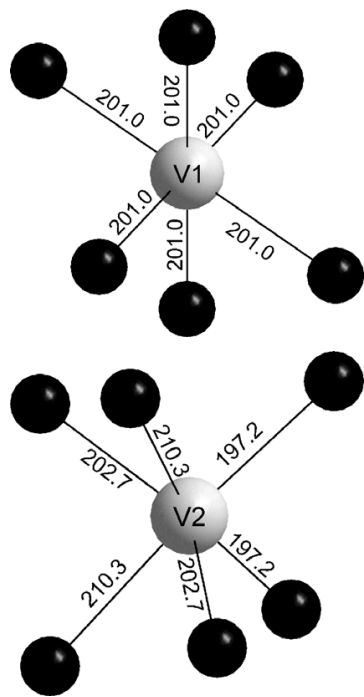

Fig. 3. $\mathrm{V}(\mathrm{O} / \mathrm{N})_{6}$ octahedra in $\mathrm{V}_{2} \mathrm{O}_{3.07} \mathrm{~N}_{0.13}$ with the bond lengths (pm) determined. in the ideal fluorite structure ( $A X_{2}$ type), leading to deviations from the ideal bixbyite composition $A_{2} X_{3}$. Unfortunately, it has not been possible to refine the occupation of the $16 c(1 / 8,1 / 8,1 / 8)$ position (empty in ideal $A_{2} X_{3}$ bixbyite structures) by 'additional' anions using $\mathrm{X}$-ray powder methods.

The $\mathrm{V} K$ edge XANES spectra of $\mathrm{V}_{2} \mathrm{O}_{3}$ (corundum) and $\mathrm{V}_{2} \mathrm{O}_{3.07} \mathrm{~N}_{0.13}$ are depicted in Fig. 4. Compared to the XANES spectrum of corundum-type $\mathrm{V}_{2} \mathrm{O}_{3}$, the XANES spectrum of $\mathrm{V}_{2} \mathrm{O}_{3.07} \mathrm{~N}_{0.13}$ exhibits a slightly higher characteristic pre-edge peak. The latter can be employed to estimate the average oxidation state of vanadium in $\mathrm{V}_{2} \mathrm{O}_{3.07} \mathrm{~N}_{0.13}$. In comparison to the reference compounds $\mathrm{V}_{2} \mathrm{O}_{3}$ and $\mathrm{V}_{2} \mathrm{O}_{5}$ the average valence of $\mathrm{V}$ in $\mathrm{V}_{2} \mathrm{O}_{3.07} \mathrm{~N}_{0.13}$ amounts to 3.25. Both the average "valence" and the distortion of the local coordination influence the pre-edge peak height. Hence, the 


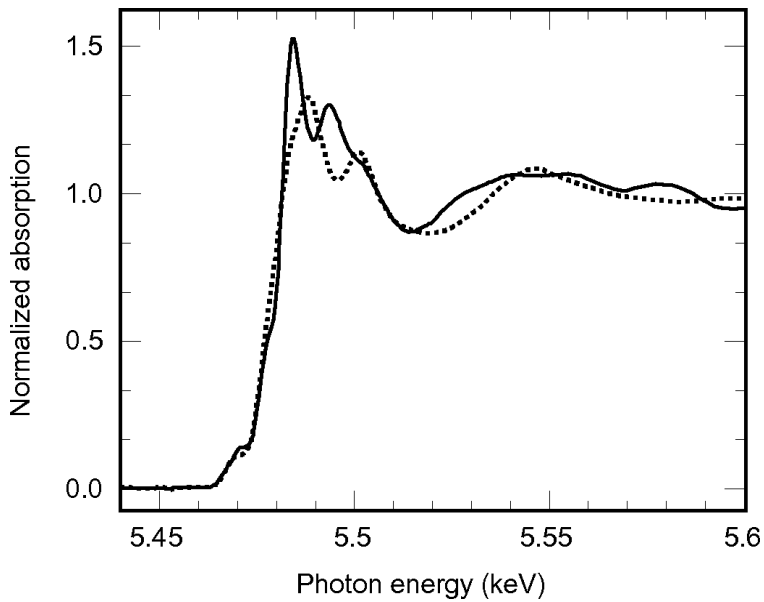

Fig. 4. Comparison of the $\mathrm{V} K$ edge XANES spectra of corundum-type $\mathrm{V}_{2} \mathrm{O}_{3}$ (dotted line) and bixbyite-type $\mathrm{V}_{2} \mathrm{O}_{3.07} \mathrm{~N}_{0.13}$ (solid line).

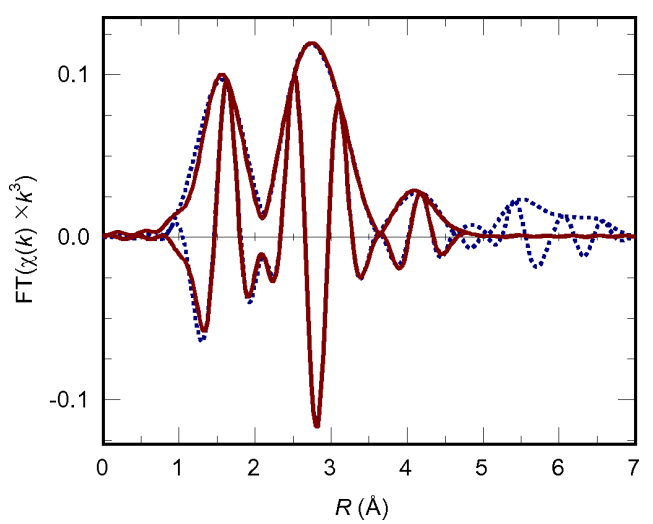

Fig. 5. Refinement of the theoretical XAFS function based on the bixbyite-type model structure (Tables 1 and 2) (solid line) to the experimental $\mathrm{V} K$ edge $\mathrm{FT}\left(\chi(k) \times k^{3}\right)$ of $\mathrm{V}_{2} \mathrm{O}_{3.07} \mathrm{~N}_{0.13}$ (dotted line).

uncertainty in the average "valence" is estimated to be about 0.05 . Provided that each nitrogen atom incorporated in the $\mathrm{V}_{2} \mathrm{O}_{3}$ structure results in an oxidation of one $\mathrm{V}^{3+}$ center to a $\mathrm{V}^{4+}$ center, the expected average formal oxidation state of vanadium in $\mathrm{V}_{2} \mathrm{O}_{3.07} \mathrm{~N}_{0.13}$ amounts to +3.26 .

The Fourier-transformed XAFS $\chi(k) \times k^{3}$ of $\mathrm{V}_{2}$ $\mathrm{O}_{3.07} \mathrm{~N}_{0.13}$ is depicted in Fig. 5. The pronounced amplitude of the V-V shells at higher distances (> $2 \AA$ ) confirms the crystallinity and the well-defined structure of $\mathrm{V}_{2} \mathrm{O}_{3.07} \mathrm{~N}_{0.13}$. The experimental $\mathrm{FT}\left(\chi(k) \times k^{3}\right)$ of $\mathrm{V}_{2} \mathrm{O}_{3.07} \mathrm{~N}_{0.13}$ can be very well simulated using a calculated $\mathrm{FT}\left(\chi(k) \times k^{3}\right)$ based on the bixbyite model structure given in Tables 1 and 2. The good agreement

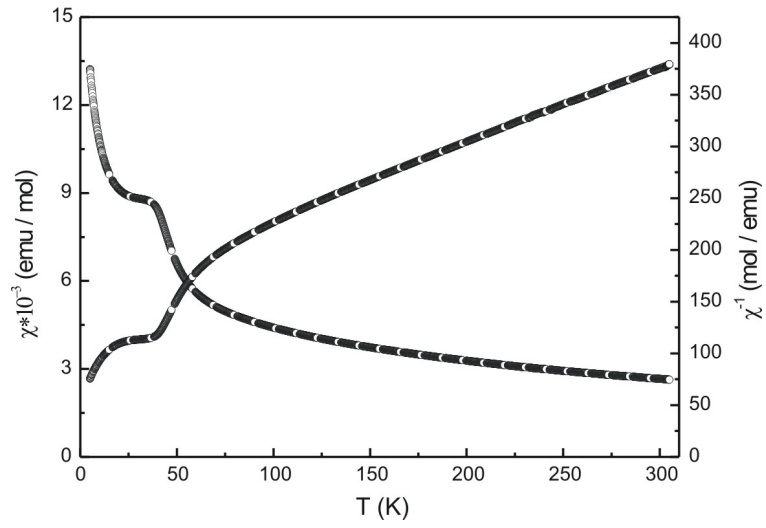

Fig. 6. Temperature dependence of the magnetic and inverse magnetic susceptibility of $\mathrm{V}_{2} \mathrm{O}_{3.07} \mathrm{~N}_{0.13}$ measured at a flux density of $40 \mathrm{kOe}$.

of the experimental and theoretical spectrum in Fig. 5 excludes the presence of considerable amounts of additional crystalline or amorphous phases in the material studied. The local structural parameters as determined from the XAFS refinement are given in Table 3. The minor deviations between the model and the refined parameters confirm the good agreement between the long-range and short-range ordered structure of $\mathrm{V}_{2} \mathrm{O}_{3.07} \mathrm{~N}_{0.13}$.

The temperature dependence of the magnetic and inverse magnetic susceptibility of the $\mathrm{V}_{2} \mathrm{O}_{3.07} \mathrm{~N}_{0.13}$ sample is presented in Fig. 6. The susceptibilities were found to be slightly field-dependent. The 30 and $40 \mathrm{kOe}$ data were already identical in the paramagnetic range. $\mathrm{V}_{2} \mathrm{O}_{3.07} \mathrm{~N}_{0.13}$ shows Curie-Weiss behavior in the temperature range 100 to $300 \mathrm{~K}$, resulting in an experimental magnetic moment of $\mu_{\text {eff }}=2.36(3) \mu_{\mathrm{B}}$ per $\mathrm{V}$ atom and a Weiss constant of $\theta_{\mathrm{P}}=-214(5) \mathrm{K}$. The experimental magnetic moment is in between the values of $\mu_{\text {theo }}\left(\mathrm{V}^{3+}\right)=2.83 \mu_{\mathrm{B}}$ and $\mu_{\text {theo }}\left(\mathrm{V}^{4+}\right)=$ $1.73 \mu_{\mathrm{B}}$. The susceptibility data nicely confirm the XANES measurements which revealed an oxidation state of +3.26 .

Below ca. $39 \mathrm{~K}$ we have observed magnetic ordering. The magnetization shows complex temperatureand field-dependent behavior. These phenomena are not yet understood and will be reported and discussed in a forthcoming manuscript. Compared with pure $\mathrm{V}_{2} \mathrm{O}_{3}$ (antiferromagnetic ordering in the range 150$162 \mathrm{~K}$ through a metal-insulator transition [14, 2931]) we have observed a drastic drop in the ordering temperature for $\mathrm{V}_{2} \mathrm{O}_{3.07} \mathrm{~N}_{0.13}$. More detailed studies on the magnetic behavior are in progress. 


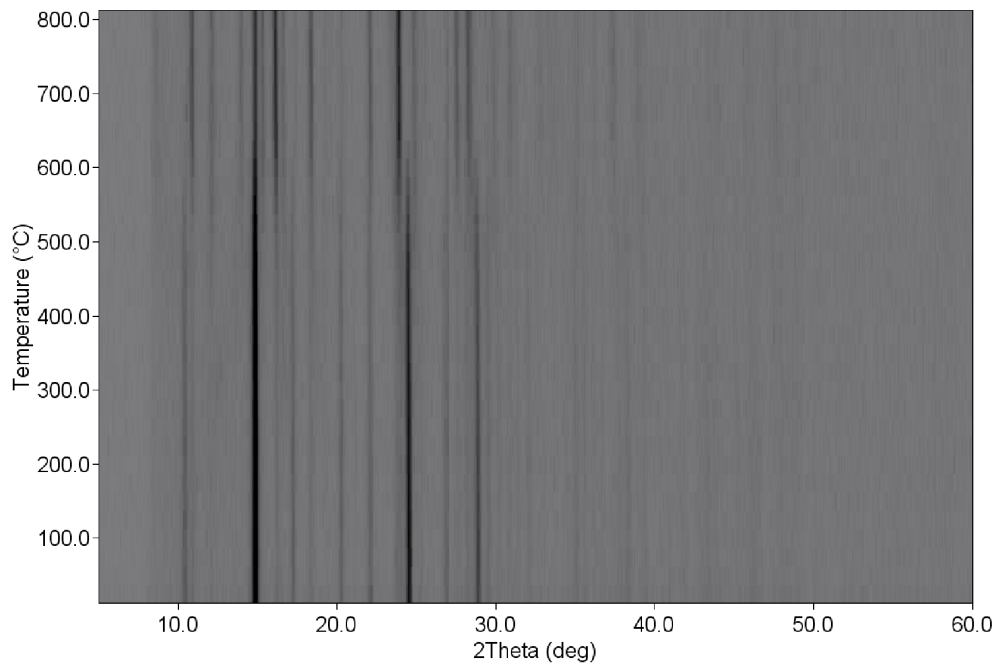

Fig. 7. High-temperature $\mathrm{X}$-ray powder patterns of bixbyite-type $\mathrm{V}_{2} \mathrm{O}_{3.07} \mathrm{~N}_{0.13}$ in argon atmosphere. Above $\sim 550{ }^{\circ} \mathrm{C}$ a corundum-type phase $\left(\mathrm{V}_{2} \mathrm{O}_{3}\right)$ is observed.
At high temperatures bixbyite-type vanadium oxide nitrides decompose. In inert gas atmosphere at $\sim 550{ }^{\circ} \mathrm{C}$ a 'transformation' (better decomposition) to a corundum-type structure was observed by high-temperature XRD measurements (Fig. 7). The resulting phase contains no nitrogen. In air, an oxidation to $\mathrm{V}_{2} \mathrm{O}_{5}$ was observed at around $350{ }^{\circ} \mathrm{C}$.

\section{Conclusions}

Vanadium oxide nitrides containing a small amount of nitrogen exhibit crystal structures not known for the pure oxides. This partial substitution can therefore be considered as a general route to new materials with interesting physical properties which has to be investigated in more detail. The bixbyite-type oxide nitride presented here is just one of several examples. In the near future we will report on a vanadium oxide nitride showing the pseudobrookite-type structure.

\section{Acknowledgements}

The authors thank B. Hahn for N/O analysis, M. Borowski for temperature-dependent X-ray measurements, and J. Nissen (ZELMI) for EDX analysis. W.H. is indebted to the Fonds der Chemischen Industrie for a $\mathrm{PhD}$ stipend. HASYLAB, Hamburg, is acknowledged for providing beamtime.
[1] S. Ito, K. R. Thampi, P. Comte, P. Liska, M. Grätzel, Chem. Commun. 2005, 268.

[2] M. Hara, T. Takata, J. N. Kondo, K. Domen, Catal. Today 2004, 90, 313.

[3] R. Nakamura, T. Tanaka, Y. Nakato, J. Phys. Chem. B 2005, 8920 .

[4] M. Lerch, J. Lerch, R. Hock, J. Wrba, J. Solid State Chem. 1997, 128, 282.

[5] J. Wendel, M. Lerch, W. Laqua, J. Solid State Chem. 1999, 142,163

[6] M. A. Taylor, M. Kilo, C. Argirusis, G. Borchardt, I. Valov, C. Korte, J. Janek, T. C. Roedel, M. Lerch, Solid State Data, Pt. A: Defect and Diffusion Forum 2005, 237-240, 479.

[7] J. H. Swisher, M. H. Read, Metal. Trans. 1972, 3, 489.

[8] M. Kerlau, O. Merdrignac-Conanec, M. Guilloux-Viry, A. Perrin, Solid State Sci. 2004, 6, 101.

[9] O. Merdrignac-Conanec, M. Kerlau, M. Guilloux-Viry, R. Marchand, N. Barsan, U. Weimar, Silicates Indust. 2004, 69, 141.
[10] G. Brauer, H. Reuther, Z. Anorg. Allg. Chem. 1973, 395, 151.

[11] B. Wang, B. C. Chakoumakos, B. C. Sales, J. B. Bates, J. Solid State Chem. 1996, 122, 376.

[12] M. W. Lumey, R. Dronskowski, Z. Anorg. Allg. Chem. 2005, 631, 887.

[13] D. B. McWhan, T. M. Rice, J. P. Remeika, Phys. Rev. Lett. 1969, 23, 1334.

[14] P. D. Dernier, M. Marezio, Phys. Rev. B 1970, 2, 3771.

[15] R. M. Moon, Phys. Rev. Lett. 1970, 25, 527.

[16] D. B. McWhan, A. Menth, J.P. Remeika, W.F. Brinkman, T. M. Rice, Phys. Rev. B 1973, 7(5), 1920.

[17] T. M. Rice, Spectroscopy of Mott Insulators and Correlated Metals, (Eds.: A. Fujimori, Y. Tokura), Springer, Berlin, 1995.

[18] F. Mila, R. Shiina, F.-C. Zhang, A. Joshi, M. Ma, V. Anisimov, T. M. Rice, Phys. Rev. Lett. 2000, 85(8), 1714.

[19] W. Kraus, G. Nolze, Bundesanstalt für Materialprüfung (BAM), Berlin (Germany) 2000. 
[20] J. Rodríguez-Carvajal, FullProf 2006, A. Program for Rietveld Refinement and Pattern Matching Analysis, 2006; see also: Satellite Meeting on Powder Diffraction of the $15^{\text {th }}$ International Congress of the IUCr, Toulouse (France) 1990, p. 127; J. RodríguezCarvajal, Physica B 1993, 192, 55.

[21] T. Ressler, J. Synch. Rad. 1998, 5, 118.

[22] J. J. Rehr, C. H. Booth, F. Bridges, S. I. Zabinsky, Phys. Rev. B 1994, 49, 12347.

[23] T. Ressler, S. L. Brock, J. Wong, S. L. Suib, J. Phys. Chem. B 1999, 103, 6407.

[24] J. C. Gilles, Bull. Soc. Chim. Fr. 1962, 2118.
[25] E. Füglein, R. Hock, M. Lerch, Z. Anorg. Allg. Chem. 1997, 623, 304.

[26] S. J. Clarke, C. W. Michie, M. J. Rosseinsky, J. Solid State Chem. 1999, 146, 399.

[27] T. Bredow, M. Lerch, Z. Anorg. Allg. Chem. 2004, 630, 2262.

[28] B. Tanguy, M. Pezat, A. Wold, J. Portier, C.R. Acad. Paris C 1976, 282, 291.

[29] R. M. Moon, Phys. Rev. Lett. 1970, 25, 527.

[30] D. B. McWhan, A. Menth, J.P. Remeika, W.F. Brinkman, T. M. Rice, Phys. Rev. B 1973, 7, 1920.

[31] B. Sass, C. Tusche, W. Felsch, F. Bertran, F. Fortuna, P. Ohresser, G. Krill, Phys. Rev. B 2005, 71, 014415. 